\title{
Autoritarismo, legitimidad carismática y culto al gobernante
}

Desde 2018, El Salvador entró en un proceso de cambio político. Dicho cambio es impulsado por un líder carismático autoritario con pretensiones divinas. El presidente de la República empuja al país hacia un régimen autoritario y pide a la población una confianza ciega en él, una confianza similar a aquella debida solamente a seres divinos. La legitimación de todo ello reside en el carisma del presidente, es decir, en la atribución de características excepcionales que las masas dan a su líder: "él sabe", "él nos cuida", "él nos defiende", "él se preocupa por nosotros", "él nos provee", "de él vienen beneficios", "no ha habido otro gobernante como él". Sobre una admiración expresada con estas y otras frases, las masas rinden honor a su líder, que se presenta como "instrumento de dios".

\section{El carácter del régimen político}

En toda sociedad moderna, existe un arreglo institucional, es decir, un conjunto de normas que regulan quién gobierna y cómo se gobierna. Algunas de esas normas están formalizadas en constituciones, códigos, tratados, leyes, reglamentos, acuerdos, decretos, etc. Otras normas no adoptan tales formas sin que ello signifique inoperancia alguna. Al contrario, incluso puede ocurrir que esta clase de normas informales tenga un mayor peso que las normas formales. En no pocas ocasiones es lo que ocurre con las costumbres que son verdaderas normas que regulan el comportamiento de las personas. Normas formales e informales coexisten y no son necesariamente excluyentes. La vida de las personas, de los grupos y de las sociedades no puede ser formalizada en su totalidad.

Al conjunto de reglas formales e informales se le conoce como "régimen", y este puede ser económico, educativo, sanitario, deportivo, jurídico, organizacional, etc. Las normas que regulan quién gobierna y cómo se gobierna constituyen un régimen político. Y, según sea el peso que tienen las normas formales sobre las normas informales sobre estos dos asuntos, así será posible distinguir si un determinado orden social es legal o no, si en un Estado priva el derecho o no. En definitiva, si quienes gobiernan se someten a las leyes o no.

La democracia puede entenderse de varias formas según la perspectiva teórica que se adopte. Hay definiciones minimalistas que igualan democracia a la realización de elecciones, con tal de que estas sean libres y competitivas. También hay definiciones maximalistas que igualan la democracia con el Es- 
tado de bienestar o con el goce de derechos económicos, sociales, culturales y ambientales, además de los derechos políticos. Entre estas dos posiciones (minimalistas y maximalistas), la democracia se entiende como régimen político. Según esta perspectiva, la realización de elecciones libres y competitivas no es suficiente para hablar de democracia, así como tampoco es necesario esperar a que la ciudadanía goce de pleno empleo, educación y salud gratuitas y universales, vivienda digna, tiempo para el ocio, un medio ambiente saludable, etc.

A nivel de régimen político, las democracias realmente existentes (que son democracias liberales) operan sobre la base de dos conjuntos normativos que regulan cómo se accede a los puestos de autoridad política y cómo debe ejercerse dicha autoridad. El primer grupo normativo refiere al sistema electoral mientras que el segundo, al control político institucional. La ausencia de estos dos pilares normativos establece la frontera, la línea de demarcación, entre un régimen democrático y uno no democrático (que puede ser autoritario o totalitario).

Sobre la base de estas premisas teóricas, ¿̇ive El Salvador ya en una dictadura o no? Para algunos sectores de oposición, la respuesta es afirmativa: con Bukele, el país vive en una dictadura. Para sectores oficialistas, la respuesta es negativa y más bien con Bukele el país vive una verdadera democracia. Para responder a la pregunta planteada, conviene hacer una aclaración previa sobre el término "dictadura". Su uso en la actual coyuntura puede ser más político que teórico-descriptivo por la carga emotivo-afectiva que dicho término conlleva. Al hablar de dictadura, se busca evocar un pasado de represión, desaparecidos, exiliados, masacres, irrespeto a los derechos humanos, gobiernos militares corruptos, golpes de Estado, fraudes electorales, etc. Ese pasado propició la movilización social contra la dictadura militar que prevaleció en el país desde 1930 hasta 1979. Quienes hablan hoy de dictadura anhelan una nueva movilización social contra esta.

En términos más teórico-descriptivos, una dictadura puede considerarse como una modalidad de régimen autoritario (incluso totalitario), pero el autoritarismo admite otras modalidades, otras formas. No es este el lugar que requiere la disquisición teórica sobre este asunto. La aclaración sirve para responder negativamente a la pregunta planteada, al menos de la siguiente forma: en este momento, El Salvador no vive una dictadura como la que vivió durante cinco décadas del siglo pasado, lo cual no quiere decir que haya que aceptar la versión oficialista de que aquí se está viviendo una verdadera democracia o que se esté profundizando una democracia que existía previamente.

Que Bukele haya llegado a ser presidente en 2019 y a obtener una mayoría legislativa en 2021 mediante elecciones no implica que El Salvador tenga una democracia a nivel de régimen político. Como se dijo antes, para esto es necesario que el ejercicio de la autoridad respete el orden legal y, para verificarlo, debe operar un eficaz control político institucional. Y esto es justamente lo que era deficitario antes de 2019 y que tiende a ser ineficaz desde el 1 de mayo de este año. 
Hay evidencia suficiente para sostener el funcionamiento deficitario del control político institucional antes de 2019. Los casos de presidentes procesados judicialmente y condenados por enriquecimiento ilícito, malversación de fondos o lavado de activos, así como los de diputados y alcaldes, son indicativos de los niveles de corrupción a los que ha llegado el país. Y las fallidas investigaciones fiscales y auditorías más la acumulación de expedientes en la sección de Probidad de la Corte Suprema de Justicia, junto con la práctica inoperancia del Tribunal de Ética Gubernamental son, entre otros, indicadores de fallas en el control político institucional. Estas y otras fallas no deben ser eludidas por los analistas políticos.

Prevalencia de las normas para decidir quién gobierna con más ineficacia o déficit en el funcionamiento del control político institucional porque se gobierna de forma autoritaria no conducen de manera lógica a la conclusión de que en El Salvador hay una democracia. Entonces, si no hay dictadura y tampoco hay democracia, ¿qué es lo que hay? La respuesta es simple: una mezcla, una combinación, un híbrido de elementos democráticos (para decidir quién gobierna) con elementos autoritarios (en el ejercicio del gobierno). El gobierno es autoritario, aunque su origen es democrático. En cambio, el régimen político no es democrático ni autoritario; es híbrido.

Ahora bien, un gobierno autoritario puede intentar perpetuarse y cambiar las normas a su favor. Es decir, un gobierno autoritario como el de Bukele puede conducir al país hacia un régimen autoritario. El ejercicio autoritario del gobierno, es decir, un gobierno que irrespeta la Constitución y demás normas legales, y que no se somete al control político institucional, puede acabar (o al menos corromper) el sistema electoral para garantizarse de esa manera su permanencia en el gobierno. Es lo que ocurrió en Venezuela y, más cerca aún, en la vecina Nicaragua. La destitución de los miembros de la Sala de lo Constitucional y del fiscal general el pasado 1 de mayo, más la neutralización del Instituto de Acceso a la Información Pública y la aprobación de la "ley Alabí", apuntan hacia la instauración de un régimen claramente autoritario. Los ataques al llamado "periodismo incómodo", más el acoso en redes sociales a toda voz disidente, apuntan en la misma dirección.

\section{El carisma frente a la institución}

En la actual coyuntura salvadoreña, se enfrentan dos principios de acción: el carisma y la institución. No se trata únicamente de dos principios, sino que estos pueden actuar en direcciones contrarias. El carisma puede oponerse a la institución y esta puede rechazar al carisma como principio de acción; por lo tanto, el carisma puede aparecer como fuente de innovación, mientras que la institución aparece como fuente de conservación. Si el carisma favorece el movimiento, la institución favorece la estabilidad, pero el carisma también puede jugar un papel importante a favor de la estabilidad; si se ha producido un cambio que ha devenido en inestabilidad, el carisma puede empujar el dinamismo hacia la estabilidad. Los líderes carismáticos que empujaron un 
cambio institucional sustantivo van a procurar estabilizar la nueva situación; van a tratar que esta se institucionalice y, al actuar en esa dirección, paradójicamente lo harán a favor de la institución, aunque ello signifique el fin de su carisma. Como suelen decir las personas que se dedican a la sociología: el desafío final de los líderes carismáticos es la institucionalización de su carisma.

No hay duda de que el actual presidente salvadoreño es un líder carismático que mueve a las masas. Ello podría representar una gran oportunidad para la sociedad salvadoreña, pues el presidente podría facilitar la consecución de unos cambios económicos, sociales, políticos, jurídicos y culturales que han sido históricamente negados por los grupos sociales con más poder económico, social, político, jurídico y cultural. No en balde se ha dicho que el Estado salvadoreño ha sido un estado capturado por estos grupos, que ponen a funcionar a las instituciones para favorecer o defender sus intereses corporativos. De hecho, el presidente suele retomar esta verdad en la narrativa con la cual ha ganado el apoyo mayoritario de la sociedad, lo cual no significa que realmente él esté poniendo todo el peso de su carisma para lograr esos cambios. Más bien, utiliza esta parte de su narrativa para mantener el rechazo social hacia "los mismos de siempre", a sabiendas de que esos "mismos de siempre" no son necesariamente los que "siempre se opusieron a los cambios". Para el presidente, "los mismos de siempre" se reducen a ARENA, el FMLN, un líder empresarial (con quien parece tener un conflicto personal-familiar) y dos periódicos (con quienes él tuvo conflicto cuando fue alcalde de San Salvador).

Por otra parte, el carisma puede actuar como fundamento para el establecimiento de relaciones de dominación. Es decir, relaciones en donde una de las partes (el líder) es capaz de hacer que la otra parte (sus seguidores, las masas) actúe según la voluntad de aquel. Las masas hacen lo que el líder dispone. No hay discusión. Unas relaciones de este tipo podrían basarse en el uso de la fuerza, pero justamente el carisma reemplaza a la fuerza. El uso de esta vuelve las relaciones de dominación unas relaciones forzadas: se obedece por la fuerza o por el temor a que se utilice la fuerza. Pero unas relaciones de dominación basadas en el carisma del líder no son forzadas. El deseo del líder es el deseo de las masas porque estas perciben al líder como alguien que las defiende, las promueve, las escucha, las representa. Y lo perciben así porque las masas están sedientas de alguien que las defienda, las promueva, las escuche y las represente.

Desde que fue alcalde de Nuevo Cuscatlán, el actual presidente ideó y puso en práctica una estrategia de comunicación política para aparecerse ante las masas como "el esperado". Esa estrategia implicó aparecer ante las masas como el que lucha a favor de ellas contra el sistema que las mantiene oprimidas. De acuerdo con aquella estrategia, habría llegado la hora de la liberación y el presidente se aparece como el liberador, probado en las situaciones adversas que "los mismos de siempre" le provocaron. Al triunfar sobre esas situaciones, el presidente se aparece ante las masas como "un instrumento de dios". Y las masas creen en él, lo han visto levantarse desde su "expulsión del partido" y la única forma de explicarse ellas mismas quién es este es decir que tiene unas cualidades excepcionales: ese es el meollo del carisma. La atribu- 
ción de unas cualidades excepcionales al líder por parte de sus seguidores es lo que los sociólogos llaman "el carisma".

El carisma no es una cualidad que tenga el líder, sino que es una cualidad atribuida a él por parte de sus seguidores. La creencia de que el líder tiene esas cualidades excepcionales, incluso de origen divino, es la base del liderazgo carismático. Como el líder se presenta ante las masas como su defensor, estas están ahora dispuestas a acompañar al líder en su misión: acabar con "los mismos de siempre" y el sistema institucional que nunca las defendió, las promovió, las escuchó ni las representó. El presidente salvadoreño repite esta argumentación bajo diversas modalidades para mantener a flote su carisma. Y algunas acciones de política pública tienen esta finalidad también. Al final de cuentas, como el carisma es una atribución basada en una percepción, el carisma solo se mantiene si da muestras de su realidad. La pandemia del covid-19 le vino como anillo al dedo al presidente porque ahora se mostró como quien está decidido a defender la vida de las masas contra "los mismos de siempre" que solo desean su muerte. En su carisma está la base de la calificación positiva que las masas hacen de su gestión durante la pandemia, pese a que para dicha gestión haya tenido que saltarse el marco legal.

\section{Legitimidad y legalidad}

Al hablar de legitimidad, se hace referencia a la aceptación social de un cierto estado de cosas. La legitimidad de un orden social es la aceptación social de este. La legitimidad de un régimen político es la aceptación social de ese régimen. En fin, la legitimidad de determinadas relaciones de dominación es la aceptación social de esas relaciones. La dominación se vuelve legítima cuando es aceptada socialmente.

Ahora bien, la aceptación social de un orden social, un régimen político o unas relaciones de dominación, se basa en dos elementos: por un lado, en la creencia social de que si se actúa de manera diferente a lo prescrito, ello conlleva un perjuicio para quien ose actuar diferente, y, por otro lado, en un sentimiento de obligación a actuar como está dispuesto. Cuestionar aquella creencia y/o poner en entredicho ese sentimiento es deslegitimar el orden, el régimen o la dominación. Esto es lo que ocurre en los procesos de cambio: se erosiona la legitimidad del viejo orden; se propone la creencia alternativa en que las cosas pueden ir mejor que como están, que lejos de un perjuicio lo que se pueden obtener son beneficios, y que, por lo tanto, no hay que sentirse obligados a acatar el viejo orden. Más bien, hay que esforzarse con construir un orden alternativo.

Es usual que los líderes carismáticos promuevan cambios (ficticios o reales) erosionando la legitimidad del statu quo. Esto es lo que hace el actual presidente cuando culpa al orden de "los mismos de siempre" como el causante de todos los males que históricamente han padecido las masas. "Hagamos historia" significa rompamos con el viejo orden y construyamos uno nuevo. Desde 
una perspectiva maniquea, los que se oponen a lo nuevo son "los mismos de siempre". Bajo esta perspectiva, no hay lugar para una oposición diferente, todos los contrarios son iguales: "babean por ver cadáveres".

En su narrativa, el presidente está dispuesto a llegar hasta las últimas consecuencias con tal de inaugurar un nuevo orden. Él estará defendiendo a las masas hasta el máximo esfuerzo, "hasta donde le den las fuerzas". En este proceso "no hay marcha atrás". Hay que desmontar el viejo orden incluyendo su "aparato ideológico", ese que servía para legitimarlo. Y si hay que saltarse las reglas, hay que hacerlo. Eso es lo que esperan las masas de su elegido. Sabiendo que aquellas reglas solo han servido para el beneficio de unos pocos, acatarlas, dejarlas intactas, es traicionar al pueblo. El presidente apela a su carisma para romper las normas. Así construye una legitimidad carismática para su orden deseado y parece erosionar la legitimidad del viejo orden basada en su marco legal.

Hay analistas que piensan que el presidente opone su legitimidad a la legalidad, que apela a su apoyo mayoritario para legitimar saltarse las reglas. En el contexto de un régimen democrático, esta visión no es correcta, pues la legitimidad no se puede oponer a la legalidad, puesto que esta es fuente de aquella. La legitimidad democrática es de carácter racional-legal, supone el "respeto a las normas". En un régimen democrático, un gobernante es legítimo gobernante porque para serlo, en primer lugar, ha sido electo bajo una regla mayoritaria. No hay duda de que el actual presidente fue legítimamente electo porque se respetó la regla que establece que para ser presidente debe contar con la mitad más uno de los votos válidos en la respectiva elección. $\mathrm{Su}$ legitimidad de origen le viene de haber respetado lo normado (el sistema electoral para la elección presidencial) y no de contar con el apoyo mayoritario de la población; porque este apoyo mayoritario podría avalar a un presidente que llega a serlo a través de un golpe de Estado, por ejemplo. Pero el golpe de Estado no es el mecanismo (el procedimiento normado) para designar a un presidente en una democracia.

En segundo lugar, un gobernante es legítimo gobernante en un régimen democrático porque en el ejercicio de su gobierno se atiene a las reglas establecidas, respeta la Constitución, las leyes, etc. La legitimidad democrática es legal; como toda legitimidad, se basa en la creencia de que no acatar las reglas podría acarrear perjuicios y en el sentimiento de obligación a cumplir las reglas. Y aquí es donde fallan aquellos analistas, porque aquella creencia y este sentimiento están ausentes en el comportamiento del presidente. Y no puede ser de otra manera porque la legitimidad bajo la que opera el presidente es carismática y no legal. El presidente apela al apoyo mayoritario para legitimar sus decisiones y acciones porque en ese apoyo está basado su carisma, tal como se explicó arriba. El presidente opone la legitimidad carismática a la legitimidad racional-legal. Al hacerlo así, el presidente expresa la oposición entre un régimen autoritario y un régimen democrático. Su afán por concentrar facultades, por centralizar las decisiones sobre políticas, la disposición de una Asamblea Legislativa que es genuflexa hacia el presidente de la República y la 
neutralización de toda clase de control político institucional sobre el Ejecutivo así lo indican.

\section{El culto al gobernante y a sus dioses}

Desde su toma de posesión del cargo, el actual presidente salvadoreño se ha empeñado en mostrarse ante la nación como un "instrumento de dios", alguien a quien "dios le habla" y sostiene, dándole fuerzas para cumplir su misión. Vistas con detenimiento, las imágenes que transmitía la televisión aquel día denotaban una ceremonia con más importancia de lo usual. No solo porque esa ceremonia tenía lugar en la plaza Barrios, frente a la catedral metropolitana y al Palacio Nacional, símbolos de poder religioso y político. Más que un traspaso de mando, aquello tenía todas las pintas de una "apoteosis", es decir, una glorificación o ensalzamiento del presidente por las masas allí reunidas.

La escena final de aquella celebración mostró al presidente y a su esposa subiendo unas escalinatas, al final de las cuales solo podía verse una luz blanca. Antes de desaparecer en medio de esa luz, el presidente y su esposa se dieron vuelta para saludar a las masas que los contemplaban desde afuera. Unos minutos después, aquella pareja desaparecía de la escena en medio de la intensa luz. Semejante escenografía parecía actualizar las ceremonias que hacían los antiguos para honrar como seres divinos o héroes a los emperadores, emperatrices u otras personas simplemente mortales.

El 9 de febrero de 2020, el presidente volvió a aparecer en escena mostrando su conexión directa con dios. Los militares que le rodeaban en el Salón Azul de la Asamblea Legislativa estaban allí para protegerlo. Eso fue lo que dijeron los responsables del operativo. Pero quizá también estaban allí para mostrar con cuál dios el presidente iba a hablar en aquel momento. Ese dios que le pidió paciencia no podía ser el dios de Jesús de Nazaret, porque de la boca del presidente solo salían amenazas: iuna semana les damos!, iuna semana! De la boca del presidente han salido maldiciones: "mil veces malditos" les increpaba a sus adversarios. De la boca del presidente han salido mentiras: este gobierno "no ha recibido ni un centavo partido por la mitad", repetía incansablemente durante la pandemia mientras el expresidente del Banco Central de Reserva mostraba, con datos, lo contrario.

El día en que el presidente asumió el cargo de comandante en jefe de las Fuerzas Armadas de El Salvador, aquel hizo jurar a los militares allí presentes lealtad hacia él antes que a la Constitución y demás leyes de la República. A las masas presentes durante su "apoteosis" también les hizo jurar lealtad hacia él. Y a los diputados presentes el 1 de mayo de 2021, durante la sesión solemne en la que asumieron su cargo, el presidente les hizo jurar de nuevo lealtad hacia él. ¿Por qué aquellos militares, masas y diputados fueron capaces de hacer lo que el presidente les pedía? Los sociólogos dirían que eso fue posible porque la relación establecida entre el presidente, los militares, las masas y los 
diputados es de dominación, basada en el carisma del presidente, un carisma cubierto con tintes religiosos.

El presidente se autodenomina "instrumento de dios" y las masas lo perciben como "el elegido" para realizar los cambios que otros o no quisieron, o no pudieron realizar. En los spots que anuncian las ya tradicionales cadenas de radio y televisión, el presidente viene bajando del cielo (desde un helicóptero que quizá le ha proporcionado el dios Marte) y abajo le esperan unos militares (especie de serafines) que le abren las puertas del salón desde el que se dirigirá al pueblo salvadoreño. La simbología sugiere que el presidente trae un mensaje de dios al pueblo.

Llama la atención que semejante simbología religiosa no sea cuestionada por los principales pastores religiosos de las diversas denominaciones cristianas. El celo por el nombre del Señor no parece devorarles. O quizá no quieren meterse en problemas con el presidente. Pero si así proceden, malos pastores son, pues dejan que se pierdan las ovejas a ellos encomendadas. O tal vez haya que considerarlos buenos administradores de los bienes materiales que poseen sus organizaciones eclesiales. Un conflicto con el presidente los podría poner en peligro. Mientras tanto, las masas creen al presidente. Tienen fe en él. Y él les alimenta esa fe: "Los salvadoreños ya me conocen y saben que jamás haría nada que no fuera en su beneficio". Pero se puede conocer a un gobernante que no es transparente en su gestión, que no se somete a los controles políticos institucionales.

El presidente exige fe en él. Pretende que las masas confíen ciegamente en sus decisiones, no importa si el éxito o fracaso de estas dependan del azar. Este es el caso con la aceptación e imposición del bitcóin como moneda de curso legal. Según el presidente, la "ley se ha trabajado a conciencia para que no afecte a nadie y para que traiga beneficios a millones de salvadoreños". Pero él mismo reconoció en cadena nacional que es una moneda volátil, así como puede subir su valor frente al dólar, así lo puede bajar; así como se puede ganar, así se puede perder. En esas condiciones, solo la diosa Fortuna puede traer beneficios a millones de salvadoreños. Y en la misma cadena nacional, el presidente reconoció que el valor del bitcóin lo fija el mercado (es decir, el dios Mercurio). Las masas no se dan cuenta de que el presidente está pidiendo que confíen en la Fortuna y en el Mercado.

Y, por si fuera poco, los altares de la religión del presidente ya han comenzado a ser instalados. En esos altares, se realizará el sacrificio. Allí depositarán sus ofrendas las masas esperando ser escuchadas por la diosa Fortuna y el dios Mercurio. ¿Cuáles son esos altares frente a los que los pastores religiosos institucionales guardan silencio? Son los cajeros automáticos donde se podrán cambiar bitcóines por dólares. iPobre pueblo que confía en Fortuna y en Mercurio! iAy de aquellos pastores que no defienden a mi pueblo! Que tan actual es la voz del profeta Ezequiel.

El presidente pide confianza en él y rechaza toda crítica a la ley del bitcóin. De nuevo recurre a la narrativa de "los mismos de siempre", aunque no sean 
justamente estos quienes han cuestionado la medida económica. Las críticas más serias vienen de reconocidos economistas, tanto nacionales como extranjeros. Son varios economistas con premio Nobel que rechazan el bitcóin. A ellos se suman las posiciones adversas del Banco Mundial, el Fondo Monetario Internacional y el Banco Interamericano de Desarrollo. Nada que ver con los mismos de siempre a los que hace referencia en su narrativa el presidente, pero él no quiere que las masas escuchen otras voces y busca descalificarlas diciendo que son "el aparato ideológico" de la oligarquía, "el coro" de los que se supone que están perdiendo sus privilegios.

La admiración de las masas por el presidente es tal que abundan imágenes de él incluso en productos de artesanía para los turistas: tasas, camisas, platos, etc. Este fenómeno se constata dando una vuelta por el mercado de artesanías en San Salvador. Él se muestra como un ícono, se propone como un modelo que debe ser imitado. Son varios los funcionarios de su gabinete los que visten, caminan y mueven los brazos imitando al presidente. La apariencia física de aquellos trata también de imitar la apariencia del presidente. Y, por si fuera poco, hay niños que son vestidos por sus progenitores como si fueran el presidente. Así las cosas, el presidente es un ídolo para las masas. Entre estas se le absolutiza a tal grado que ial presidente no se le toca!

Para mantener este culto, el presidente necesita reafirmar constantemente su carisma. Esto significa que aquel debe probar una y otra vez que es poseedor de las características que las masas le atribuyen. Por eso tiene que repartir beneficios (milagros) constantemente: víveres, dinero, computadoras, camas hospitalarias, vacunas, etc. El día en que el presidente no reparta beneficios, aunque sea simbólicos, ese día entrará en crisis su carisma. El día en que las decisiones del presidente perjudiquen claramente a las masas, ese día el encanto comenzará a desaparecer. Cuando su dominación deje de ser carismática, ese día entonces tendrá que recurrir a la represión, a la fuerza bruta. El dios Marte vendrá en su auxilio. Entonces las masas se darán cuenta de que el presidente no es un dios a quien honrar. Ese día será un día de lamentación. En aquel día, se cumplirá la profecía: "Y tu desprecio ha subido al Altísimo y tu soberbia, al Fuerte. Y el Altísimo ha mirado sus tiempos y están acabados, y a sus siglos y están completos" (Libro IV de Esdras, 11, 43-44). 